\title{
Leishmania major large RAB GTPase is highly immunogenic in individuals immune to cutaneous and visceral leishmaniasis
}

\author{
Rym Chamakh-Ayari ${ }^{1,2}$, Mehdi Chenik', Ahmed Sahbi Chakroun ${ }^{3}$, Narges Bahi-Jaber ${ }^{4}$, Karim Aoun $^{1}$
} and Amel Meddeb-Garnaoui ${ }^{*}$

\begin{abstract}
Background: We previously identified a Leishmania (L.) major large RAB GTPase (LmIRAB), a new atypical RAB GTPase protein. It is highly conserved in Leishmania species while displaying low level of homology with mammalian homologues. Leishmania small RAB GTPases proteins have been involved in regulation of exocytic and endocytic pathways whereas the role of large RAB GTPases proteins has not been characterized yet. We report here the immunogenicity of both recombinant rLmIRAB and $r L m I R A B C$, in individuals with immunity against $L$. major or L. infantum.
\end{abstract}

Methods: PBMC were isolated from individuals cured of $L$. major $(C C L m)$ or from healthy individuals. The latter were subdivided into high or low IFN- $\gamma$ responders. Healthy high IFN- $\gamma$ responders, considered as asymptomatics, were living in an endemic area for L. major (HHRLm) or L. infantum (HHRLi). Healthy low IFN- $\gamma$ responders (HLR) were considered as naïve controls. Cells from all volunteers were stimulated with rLmIRAB or rLmIRABC. Cytokines were analysed by CBA and ELISA and phenotypes of IFN- - -producing cells were analysed by flow cytometry.

Results: Both rLmIRAB and rLmIRABC induced high significant levels of IFN- $\gamma$ in CCLm, HHRLm and HHRLi groups. Phenotype analysis of rLmIRAB and rLmIRABC-stimulated T cells in CCLm individuals showed a significant increase in the percentage of specific IFN- $\gamma$-producing CD4+ and CD8+ T cells. rLmIRAB induced significant granzyme B levels in CCLm and HHRLm. Low but significant granzyme B levels were detected in naïve group. IL-10 was detected in immune and naïve individuals.

Conclusion: We showed that rLmIRAB protein and its divergent carboxy-terminal part induced a predominant Th1 response in individuals immune to $L$. major or $L$. infantum. Our results suggest that $r L m I R A B$ and $r L m I R A B C$ proteins are potential cross-species vaccine candidates against cutaneous and visceral leishmaniasis.

Keywords: RAB GTPase, Vaccine, Human leishmaniasis, Leishmania, Cross-protection

\section{Background}

Leishmaniasis is a vector-borne disease caused by intracellular protozoan parasites belonging to the genus Leishmania. This disease is characterized by a spectrum of clinical manifestations determined by Leishmania species and the host immune response against the parasite. It ranges from asymptomatic infections to cutaneous or fatal visceral forms [1]. The control of leishmaniasis

\footnotetext{
* Correspondence: amel.garnaoui@yahoo.fr; amel.garnaoui@pasteur.tn ${ }^{1}$ Laboratory of Medical Parasitology, Biotechnology and Biomolecules, LR11-IPT-06, Institut Pasteur de Tunis, Tunis, Tunisia

Full list of author information is available at the end of the article
}

mainly relies on chemotherapy, which has been hampered by drug toxicity and the emergence of drug resistant strains [2]. In endemic areas, healing appears to confer life-long immunity to re-infection suggesting the feasibility of a vaccine in humans. Cell-mediated immunity is essential for resistance and the establishment of a protective immunity against infection. The cellular immune responses developed during leishmaniasis have been extensively studied in mouse models, mainly using Leishmania (L.) major infection. In resistant mice, T-helper 1 (Th1)-mediated response promotes interferon- $\gamma$ (IFN- $\gamma$ ) production, which activates infected macrophages to kill 
parasites via nitric oxide production leading to the control of parasite burden and lesion healing [3, 4]. Resistance to re-infection is mediated by the generation of memory CD4+ T cells in these mice [5]. Conversely, in susceptible $\mathrm{BALB} / \mathrm{c}$ mice, a Th2 dominant response is observed, leading to the production of anti-inflammatory cytokines, such as IL-4, IL-5 and IL-13, which promotes disease progression in human leishmaniasis, a clear Th1- or Th2polarized immune response similar to murine model is never observed. However, healing and resistance to reinfection is generally correlated with the development of a dominant antigen-specific Th1 cell responses and IFN- $\gamma$ production [5]. CD4+ T cells as well as CD8+ cells play major roles in the healing process during human Leishmania infection, mainly through IFN- $\gamma$ production [6-8]. More recently, a balance between the proportion of CD4+ and CD8+ cells has been reported to be important for leishmaniasis healing. Multifunctional $\mathrm{T}$ CD4+ cells producing IFN- $\gamma$, TNF- $\alpha$ and IL-2 were correlated with protection against murine experimental leishmaniasis and were recently detected in individuals healed of $L$. braziliensis infection. Many studies have focused on the identification of antigens inducing Leishmania-specific CD4+ and CD8+ T cell responses $[9,10]$. Several Leishmania recombinant proteins have been investigated as vaccine candidates in animal models and variable results regarding the ability to induce protection were observed. A number of Leishmania proteins were specifically recognized by Th1 cells of humans exposed to the parasite and were considered as potential vaccine candidates [9-12]. However, to date there is yet no protective vaccine against human leishmaniasis.

We previously identified a new atypical $L$. major large RAB protein, LmlRAB [13]. LmlRAB (610 aa) displays a conserved domain located in amino-terminal part (34284) and contains characteristic signatures of RAB proteins, GTP binding domains, RAB specific domains, RAB subfamily-specific domains and a prenylation site in the last 4 amino acids. In addition, LmIRAB shows a divergent carboxy-terminal domain (LmIRABC) (285610) that is specific to Leishmania species [13]. RAB GTPases are well known for their key role in regulation of exocytic and endocytic pathways in eukaryotic cells and more globally as specialized trafficking pathways proteins that are involved in the fusion of phagosomes with various endocytic organelles [14]. Several Rab GTPases genes were identified in Leishmania parasites genomes in silico. However, only some of them have experimentally been shown to play a role in the regulation of exocytic and endocytic pathways. Rab5 plays a major role in hemoglobin trafficking and Rab7 is involved in the degradation of endocytosed hemoglobin, which is required for optimal Leishmania growth $[15,16]$. Recently, Bahl et al. [17] also showed that Rab1 plays an essential role in the regulation of the secretory pathway in Leishmania. An isoform of Rab5 was described as a specific regulator of different modes of endocytosis [18].

To identify vaccine candidate molecules against human leishmaniasis, we evaluated the ability of the recombinant LmlRAB (rLmlRAB) and its divergent carboxy-terminal part, rLmIRABC, to induce cellular immune responses in individuals with protective immunity against $L$. major or L. infantum infection.

\section{Methods \\ Study population and samples}

Peripheral blood samples were collected from 91 donors (age ranging from 18 to 60 years). Human groups included individuals who have recovered from CL due to L. major (CCLm) and healthy individuals with no history of leishmaniasis but with a probable asymptomatic infection. These individuals were recruited from two wellcharacterized endemic foci located in central Tunisia for cutaneous leishmaniasis (CL) due to L. major (Guettitir) and visceral leishmaniasis (VL) due to $L$. infantum (Dkhila).

Cured individuals were recruited based on the following criteria: (i) living in endemic L. major foci; (ii) welldocumented medical records; (iii) presence of typical scars; and (iv) high IFN- $\gamma$ response to Soluble Leishmania Antigens (SLA) $(>300 \mathrm{pg} / \mathrm{ml})$. Healthy individuals with a probable asymptomatic L. major (Healthy High Responders, HHRLm) or L. infantum infection (HHRLi), were recruited from an endemic area for $\mathrm{CL}$ or $\mathrm{VL}$, respectively, with high IFN- $\gamma$ response to SLA (> $300 \mathrm{pg}$ / $\mathrm{ml}$ ) and no scars. Healthy individuals with no or low IFN- $\gamma$ response to SLA $(<100 \mathrm{pg} / \mathrm{ml})$ (Healthy Low Responders, HLR) and with no history of leishmaniasis, were recruited from Tunis, a low endemicity area, and were considered as naïve controls. Exclusion criteria were immunosuppressive diseases other than leishmaniasis, long-term treatment and pregnancy. The different human groups used in this study are detailed in Table 1.

\section{Cloning of LmIRAB and plasmid constructions}

The full-length Lmlrab gene (1,833 bp; GenBank: AY962589) and LmlrabC, corresponding to the divergent carboxy-terminal part (1,286 bp) were amplified by PCR from genomic DNA of L. major (MHOM/ TN/94/GLC94) using specific primers (Table 2). The purified PCR products were digested with specific restriction enzymes and cloned in pET-22b (+) expression vector (Novagen, EMD Millipore). The transformed BL21 E. coli were screened for the presence of recombinant plasmid with the Lmlrab or LmlrabC insert by gene-specific PCR. Isolated positive clones were subsequently sequenced. 
Table 1 Study population

\begin{tabular}{lllll}
\hline Status & Group ID & Number & Average age & Leishmania species \\
\hline Cured from CL & CCLm & 30 & $43.34 \pm 13.07$ & L. major \\
Healthy high responder (L. major) & HHRLm & 18 & $39.17 \pm 10.40$ & L. major \\
Healthy high responder (L. infantum) & HHRLi & 26 & $35.75 \pm 9.55$ & L. infantum \\
Healthy low responders & HLR & 17 & $30.76 \pm 5.73$ & - \\
\hline
\end{tabular}

Abbreviations: CCLm Cured from cutaneous leishmaniasis due to L. major, HHRLm Healthy High Responders (L. major), HHRLi Healthy High Responders (L. infantum), HLR, naïves control

The recruitment and peripheral blood sampling of different groups including cured from $C L$ due to $L$. major (CCLm) and individuals with a probable asymptomatic L. major (HHRLm) or L. infantum infection (HHRLi), were performed in endemic foci for CL due to $L$. major and VL due to $L$. infantum. Healthy individuals with no history of leishmaniasis, used as naïve controls (HLR) were recruited from a low-endemic area

\section{Production of purified recombinant rLmIRAB and its divergent carboxy-terminal part rLmIRABC}

BL21 E. coli strain cells harboring the recombinant plasmid pET-LmlRAB and pET-LmIRABC were grown in LB medium, induced with $1 \mathrm{mM}$ isopropyl-1-thio- $\beta$-dgalactopyranoside (IPTG) for $4 \mathrm{~h}$ and lysed. Recombinant LmlRAB-(His) ${ }_{6}$ (rLmlRAB) and LmlRABC-(His $)_{6}$ (rLmlRABC) were synthesized as insoluble proteins. These proteins were solubilized in $6 \mathrm{M}$ guanidine- $\mathrm{HCl}$ and purified by affinity chromatography over Ni-NTA resin using an imidazole gradient elution (GE Healthcare, Biosciences, Uppsala, Sweden). The Purity was demonstrated by $12 \%$ SDS-polyacrylamide gel followed by Coomassie blue staining (data not shown). Western blot analysis was performed using polyclonal antibodies directed against the divergent carboxy-terminal part rLmlRABC (Fig. 1).

Purified recombinant proteins were also tested for the presence of LPS using $10 \mu \mathrm{g} / \mathrm{ml}$ of polymyxin B (SigmaAldrich, Steinheim, Germany) or $100 \mu \mathrm{g} / \mathrm{ml}$ of proteinase K (Invitrogen, Darmstadt, Germany) in PBMCs stimulated cultures. IL-10 production was strongly inhibited by proteinase $\mathrm{K}$ treatment whereas polymixin $\mathrm{B}$ did not affect this activity, indicating the absence of LPS contamination in the purified recombinant proteins.

\section{Analysis and comparison of DNA and amino acid sequences}

Nucleotide and deduced amino acid sequences of LmIRAB were downloaded from the GenBank database using the ID: AY962589.1 and used as a query to run the NCBI-Blast program hosted on the online Kinetoplatid Genomics Ressources (tritrypdb.org). The similarity analysis of LmlRAB sequences was performed over the whole genome sequences of the following Leishmania strains (L. major strain Friedlin; L. major strain SD 75.1; L. major strain LV39c5; L. infantum strain JPCM5; L. donovani strain BPK282A1; L. tropica strain L590; L. mexicana strain U1103; L. amazonensis strain M2269; L. aethiopica strain L147; L. braziliensis strain M2904 and L. braziliensis strain M2903). The corresponding genomic sequences were downloaded from the TriTrypDB plateform and translated into amino acid sequences using Geneious Pro version (3.6.2) [19]. Pairwise and overall global alignments were generated. Finally, the domains annotations were edited over the alignment to assess global and local similarities.

\section{Preparation of soluble Leishmania promastigote antigens (SLA)}

SLA were prepared from promastigote stationary phase parasite cultures of L. major (MHOM/TN/94/GLC94). Parasites were washed in $1 \times$ phosphate-buffered saline (PBS), centrifuged at $1,000 \times \mathrm{g} / 10 \mathrm{~min}$ at $4{ }^{\circ} \mathrm{C}$ and supernatants were removed. The pellets were resuspended in lysis buffer $(50 \mathrm{mM}$ Tris $/ 5 \mathrm{mM}$ EDTA/HCl, pH7.1 ml/ $1 \times 10^{9}$ parasites), subjected to three rapid freeze/thaw cycles followed by three pulses of $20 \mathrm{~s} / 40 \mathrm{~W}$ with sonicator. Samples were centrifuged at $5,000 \times g$ for $20 \mathrm{~min}$ at $4{ }^{\circ} \mathrm{C}$, and supernatants were collected, aliquoted and stored at $-80{ }^{\circ} \mathrm{C}$ until use. Protein quantification was performed using Bradford method.

\section{Cell culture and stimulation}

Peripheral blood mononuclear cells (PBMCs) were isolated from blood by density centrifugation through

Table 2 Primers used for cloning of $L m I R A B$ and $L m I R A B C$ and plasmid constructions

\begin{tabular}{|c|c|c|c|c|}
\hline Name & Type & Primer sequences & Primer sequences & Restriction site \\
\hline F-Ras1a & Forward & rlmlrab & 5'-GCCCATATGAGCTCAACTGGTCAGCATG-3' & Ndel \\
\hline F-Ras3a & Forward & rlmlrabc & 5'GCCCATATGATCATCGCCGATGTGTCG-3' & Ndel \\
\hline R-Ras3b & Reverse & rlmlrab/rlmlrabc & 5'-GCCGCGGCCGCCCAGTACGCAGCAGTTGC-3' & Notl \\
\hline
\end{tabular}

Reverse and forward primers containing at their $5^{\prime}$ end a restriction site (underlined) were used to amplify the full length LmIRAB ORF and its carboxyl part LmIRABC. The amplified double-stranded DNA were first digested with Ndel and Notl and then inserted into the corresponding cloning sites in the pET-22b + vector (Novagen) 


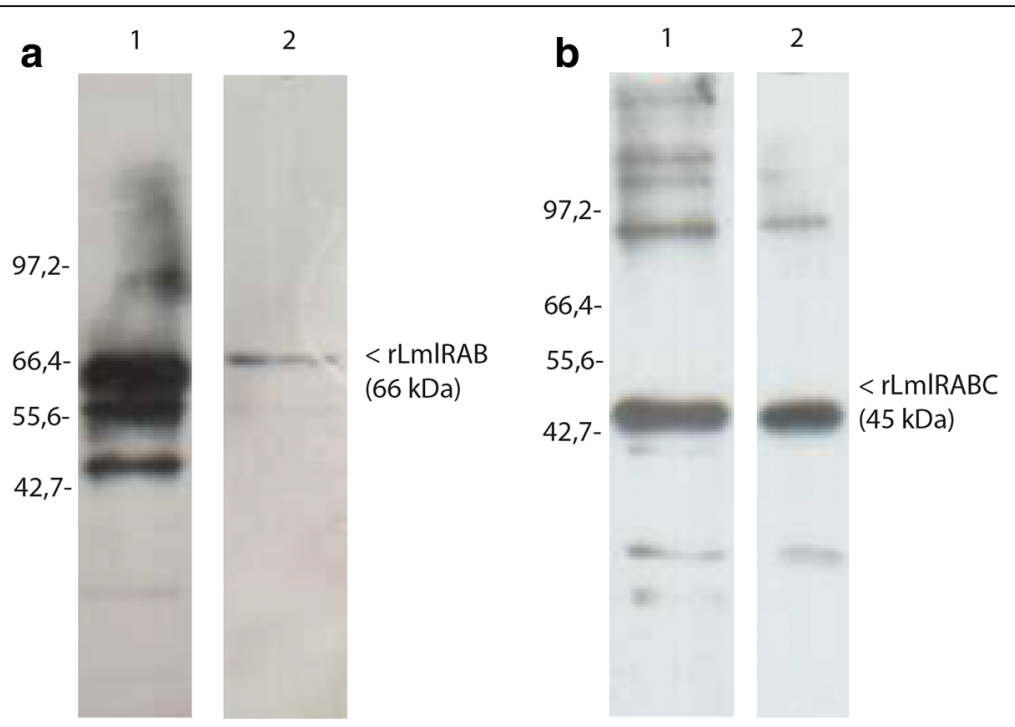

Fig. 1 Expression of recombinant rLmIRAB and rLmIRABC in E. coli. Recombinant rLmIRAB as well as its carboxyl terminal part rLmIRABC were synthesized in BL21, purified by affinity chromatography over Ni-NTA resin. Western blot analysis shows the reactivity of the polyclonal anti-LmIRAB against the insoluble fraction of $E$. coli expressing both proteins rLmIRAB (a Lane 1) and LmIRABC (b Lane 1). The purified proteins rLmIRAB (a Lane 2) and $r L m \mid R A B$ (b Lane 2) were also analyzed

Ficoll-Hypaque (GE Healthcare Bio-Sciences AB, Uppsala, Sweden). Cells were cultured in RPMI 1640 supplemented with $10 \%$ heat inactivated FBS, $100 \mathrm{IU} / \mathrm{ml}$ penicillin, $100 \mu \mathrm{g} / \mathrm{ml}$ streptomycin, $2 \mathrm{mM} \mathrm{L}$-glutamin, $50 \mu \mathrm{M}$ 2-mercaptoethanol, $1 \mathrm{mM}$ sodium pyruvate and $1 \times$ non essential amino acid. Briefly, cells were plated in 96 well tissue culture plates (TPP, Switzerland) and were kept with media alone (unstimulated) or stimulated with $10 \mu \mathrm{g} / \mathrm{ml}$ phytohemagglutinin (PHA) (Sigma-Aldrich) used as a positive control or $10 \mu \mathrm{g} / \mathrm{ml}$ SLA or $10 \mu \mathrm{g} / \mathrm{ml}$ rLmIRAB or rLmlRABC, in a $5 \% \mathrm{CO}_{2}$ humidified atmosphere at $37^{\circ} \mathrm{C}$ for 5 days.

\section{ELISA}

IFN- $\gamma$ and Interleukine-10 (IL-10) levels were measured, by Enzyme-linked immunosorbent assay (ELISA), in cell culture supernatants that were collected after $120 \mathrm{~h}$, centrifuged and stored at $-80{ }^{\circ} \mathrm{C}$ until use. Human IFN- $\gamma$ or IL-10 ELISA Sets (BD Biosciences) were used according to manufacturer's instructions. Results were interpolated from a standard curve using recombinant cytokines and were expressed in $\mathrm{pg} / \mathrm{ml}$.

\section{Cytometric Bead Array assay (CBA)}

Granzyme B and tumor necrosis factor-alpha (TNF- $\alpha$ ) were detected and quantified from culture supernatants $(50 \mu \mathrm{l})$ of PBMC exposed for $120 \mathrm{~h}$ to PHA $(10 \mu \mathrm{g} / \mathrm{ml})$, SLA $(10 \mu \mathrm{g} / \mathrm{ml})$, rLmlRAB or rLmlRABC $(10 \mu \mathrm{g} / \mathrm{ml})$, using the BD CBA Human Soluble Protein Flex Set system, according to the instructions of the manufacturer
(BD Biosciences). Granzyme B was analysed only in CCLm, HHRLm and HLR groups. In order to quantitate samples, the $\mathrm{BD}^{\mathrm{m}}$ CBA Human Soluble Protein Flex Standard was performed for each cytokine and in each experiment. Data were acquired by flow cytometry (FACS Canto II, BD Bioscience) using 2color detection. Flow Cytometric Analysis Program Array (FCAP Array ${ }^{\text {tmi }}$; BD Biosciences) software was used for samples analysis.

\section{Intracellular cytokine staining and flow cytometry}

Freshly isolated PBMC from CCLm group were stimulated with PMA $(50 \mathrm{ng} / \mathrm{ml}) /$ ionomicyn $\left(10^{-6} \mathrm{M}\right)$ for $6 \mathrm{~h}$ (positive control) or SLA $(10 \mu \mathrm{g} / \mathrm{ml})$ or rLmlRAB or rLmlRABC $(10 \mu \mathrm{g} / \mathrm{ml})$ for $120 \mathrm{~h}$, or kept with medium alone. Cells were treated with Golgistop (BD Biosciences) for the last $6 \mathrm{~h}$ of culture, then washed and incubated with antibodies: FITC CD3, PerCPcy5.5 CD4, APC-H7 CD8 or PerCPcy5.5 CD8, and PE-Cy7 CD69 or PE CD69 (BD Biosciences), for $20 \mathrm{~min}$ at $4{ }^{\circ} \mathrm{C}$. For intracellular IFN- $\gamma$ detection, cells were fixed and permeabilized using BD Cytoperm/cytofix plus kit (BD Biosciences) according to manufacturer's instructions and labelled with PE-anti-IFN- $\gamma$ mAb (intracellular formulation) (BD Biosciences). $\mathrm{BD}^{\mathrm{mm}}$ CompBeads Set Anti-Mouse Ig, k (Anti-Mouse Ig, k/Negative Control (FBS) Compensation Particles Set) (BD Biosciences) was used for compensation controls. Analysis was performed with DIVA software. 


\section{Statistical analysis}

Data analysis was performed with Stata statistical software (StataCorp. 2009. Stata Statistical Software: Release 11. College Station, TX: StataCorp LP.). We used nonparametric statistical tests because of the low number of individuals in some groups and of the heterogeneity of the standard deviation between groups. Results are expressed as mean \pm standard deviation (SD) and a $P$-value of $<0.05$ was considered significant in all cases (granzyme B and TNF- $\alpha$ ). In the statistical analysis of cytokine level and phenotyping, we used Wilcoxon signed-rank test to compare median levels of cytokines (IFN- $\gamma$ and IL-10) or percentage of cells producing IFN- $\gamma$ after different stimulations in paired data. Kruskal-Wallis rank test was used for intergroups analysis on normalized data after deducting the non-stimulated value.

\section{Results}

LmIRAB is highly conserved among Leishmania species

Screening of effective Leishmania vaccine candidates requires the identification of antigens that are highly conserved among Leishmania species. We previously showed that the LmlRAB is highly conserved among Leishmania strains and species [13]. In order to confirm this finding and given the availability of recent data on Leishmania genome, we performed a similarity analysis using additional Leishmania strains and species.
As expected, Leishmania large RAB GTPases proteins are conserved among Leishmania strains and species, with similarity ratios ranging between 98.9 to $63.7 \%$ (Table 3). In addition, alignments of specific LmlRAB regions ranging from amino acid 1 to 183 and 184 to 611, respectively identified as $\mathrm{N}$ - and C-terminal parts, revealed that the $\mathrm{N}$-terminal regions are more conserved than the C-terminal ones, with a similarity ratio span of 98.9 to $74.3 \%$ for the N-terminal and of $98.9 \%$ falling to $59.3 \%$ for the C-terminal (Table 3). Interestingly, RAB GTPases domains (binding and functional domains and the prenylation site) are highly conserved among all studied Leishmania strains and species (Fig. 2).

\section{rLmIRAB and rLmIRABC induce a dominant Th1 cytokine pattern in individuals immune to $L$. major or $L$. infantum infection}

We analysed IFN- $\gamma$, granzyme B, TNF- $\alpha$ and IL-10 levels in PBMC from individuals cured of CL (CCLm), or with a probable asymptomatic $L$. major (HHRLm) or L. infantum (HHRLi) infection as well as in naïve control subjects (HLR), following stimulation with rLmlRAB or rLmlRABC (Fig. 3). Results were compared to those observed after PHA (data not shown) or SLA stimulation. It should be noted that asymptomatic infection was strongly suggested by high IFN- $\gamma$ levels in response to SLA in individuals living in endemic areas for Leishmania infection $(>300 \mathrm{pg} / \mathrm{ml})$.

Table 3 Similarity ratios produced by pairwise alignment of Lm|Rab with Leishmania strains ortholog sequences

\begin{tabular}{|c|c|c|c|c|c|c|c|c|c|}
\hline \multirow[t]{4}{*}{ Leishmania strain } & \multirow{4}{*}{$\begin{array}{l}\text { Chromosome/ } \\
\text { Gene ID }\end{array}$} & \multirow{4}{*}{$\begin{array}{l}\text { Genomic } \\
\text { coordinates }\end{array}$} & \multirow[t]{4}{*}{ Product $^{a}$} & \multirow{2}{*}{\multicolumn{2}{|c|}{$\begin{array}{l}\text { Similarity \% } \\
\text { L. major HV P25 } \\
\text { (Tunisia) }\end{array}$}} & \multirow{2}{*}{\multicolumn{2}{|c|}{$\frac{\text { Similarity \% }}{\mathrm{N} \text {-ter }}$}} & \multirow{2}{*}{\multicolumn{2}{|c|}{$\frac{\text { Similarity \% }}{\text { C-Ter }}$}} \\
\hline & & & & & & & & & \\
\hline & & & & \multicolumn{2}{|c|}{ AY962589.1 } & \multicolumn{2}{|c|}{ AY962589.1 } & \multicolumn{2}{|c|}{ AY962589.1 } \\
\hline & & & & $\mathrm{N}(\%)$ & $P(\%)$ & $\mathrm{N}(\%)$ & $\mathrm{P}(\%)$ & $\mathrm{N}(\%)$ & $\mathrm{P}(\%)$ \\
\hline L. major Friedlin & LmjF.31.0860 & $315900-317732(-)$ & ras-like small GTPases, putative & 99.60 & 98.90 & 99.5 & 98.9 & 99.6 & 98.8 \\
\hline L. major strain SD 75.1 & $J \mathrm{H} 605118.1$ & 298109-299941 (-) & not yet annotated & 99.60 & 98.90 & 99.5 & 98.8 & 99.5 & 98.9 \\
\hline L. major strain LV39c5 & KB217892.1 & $1129713-1131545$ & not yet annotated & 99.50 & 98.70 & 99.5 & 98.9 & 99.6 & 98.6 \\
\hline L. infantum JPCM5 & LinJ.31.0890 & $322703-324532(-)$ & ras-like small GTPases, putative & 94.40 & 91.00 & 94.00 & 94.5 & 93.0 & 89.3 \\
\hline L. donovani BPK282A1 & LdBPK_310890.1 & $329426-331255(-)$ & not yet annotated & 93.30 & 90.80 & 94.2 & 95.1 & 92.6 & 88.6 \\
\hline L. tropica L590 & KE147396.1 & 108776-110605 (-) & not yet annotated & 94.30 & 90.70 & 90.4 & 94.0 & 87.1 & 89.0 \\
\hline L. tropica L590 & KE147396.1 & 100399-102228 (-) & not yet annotated & 94.30 & 90.70 & 95.4 & 95.1 & 93.6 & 89.3 \\
\hline L. mexicana U1103 & LmxM.30.0860 & 324259-326091 (-) & ras-like small GTPases, putative & 93.10 & 90.50 & 96.2 & 90.2 & 88.0 & 79.4 \\
\hline L. amazonensis M2269 & KE390271.1 & $700-2532$ & not yet annotated & 94.20 & 90.50 & 90.4 & 89.6 & 87.1 & 78.3 \\
\hline L. aethiopica L147 & AUMB01001544.1 & $10483-12315$ & not yet annotated & 88.70 & 82.70 & 95.4 & 93.4 & 93.8 & 89.5 \\
\hline L. aethiopica L147 & AUMB01001560.1 & 101-1933 & not yet annotated & 88.10 & 81.70 & 95.4 & 93.4 & 93.8 & 89.5 \\
\hline L. braziliensis M2904 & LbrM.31.1020 & $360616-362445(-)$ & ras-like small GTPases, putative & 74.50 & 63.80 & 78.1 & 74.3 & 72.9 & 59.3 \\
\hline L. braziliensis M2903 & LbrM2903_31_1140 & $408882-410711(-)$ & ras-like small GTPases, putative & 74.40 & 63.70 & 78.3 & 74.3 & 72.9 & 59.3 \\
\hline
\end{tabular}

${ }^{a}$ According to TriTrypDB release 24 (15/04/2015) www.tritrypdb.org

For each of the selected Leishmania strains, the chromosome (or gene ID if chromosome were not assembled yet), the genomic coordinates and the gene product as described in the TriTrypDB server (Release 24 of 15/04/2015) is provided. Similarity ratios were drawn from pairwise alignments of both nucleic (columns noted "N") and peptidic (columns noted " $\mathrm{P}$ ") sequences, regarding the entire gene sequence (column named "L. major HV P25 (Tunisia)"), the so called N-terminal region ranging from residue 1 to 183 (column named "N Ter") and the so called C-terminal region ranging from residue 184 to 611 (column named "C Ter") 


\begin{tabular}{|c|c|c|c|c|c|c|c|c|c|c|c|c|c|}
\hline \multirow{2}{*}{ Leishmania strains } & \multicolumn{4}{|c|}{ Binding domains } & * & \multicolumn{5}{|c|}{ Functional domains } & \multicolumn{3}{|c|}{ Subfamily-specific domains } \\
\hline & G1 & G2 & G3 & G4 & PS & F1 & F2 & F3 & F4 & F5 & SF1 & SF2 & SF3 \\
\hline L. major HV P25 - AY962589.1 & GDYSVGKT & WDTAGLE & NKID & YSEVSAK & $\operatorname{ccvl}$ & VGTDF & RLQIW & KYAASY & TLRNA & CVEDVTT & KEYVFK & SLIKRLLSIPASGASPR & SSLHSVVGRHLSIVADHMPHLDQSS IMV \\
\hline L. major Friedlin - LmjF.31.0860 & $\cdots$ & $\ldots \ldots \ldots$ & $\ldots$ & ........ & $\cdots$ & .... & ..... & ...... & $\cdots \cdots$ & $\cdots$ & ...... & $\ldots \ldots \ldots+\ldots \ldots+\cdots$ & 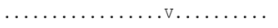 \\
\hline L. major strain SD 75.1 - JH605118.1 & .... & ....... & $\ldots$ & & & ..... & $\ldots \ldots$ & ....... & ..... & & ...... & ......... & 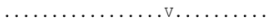 \\
\hline L. major strain LV39C5 - KB217892.1 & … & an. & $\cdots$ & & & … & $\cdots \cdots$ & ...... & $\cdots \cdots$ & & ...... & n.w. & n.m. \\
\hline L. infantum JPCM5 - LinJ.31.0890 & ... & ........ & ... & .A. . & & ..... & ..... & ....... & ..... & & ...... & 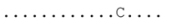 & 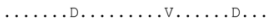 \\
\hline L. donovani BPK282A1 - LdBPK_310890.1 & $\cdots$ & ....... & $\cdots$ & .A... & & .... & .... & … & .... & & ..... & ............. & 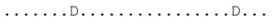 \\
\hline L. tropica L590 - KE147396.1 [108776 - 110605] (-) & ..... & ....... & ... & ..... & $\cdots$ & ..... & .... & ...... & ..... & $\cdots$ & ...... & .............. & $\ldots \ldots \ldots$ D....... $, \ldots \ldots, G \ldots$ \\
\hline L. tropica L590 - KE147396.1 [100399 - 102228] (-) & .. & ....... & ... & ... & .. & ..... & ..... & ....... & $\ldots$. & & ...... & 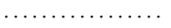 & $\ldots \ldots \ldots$ D $\ldots \ldots \ldots$. $\ldots \ldots, \ldots, \ldots$ \\
\hline L. mexicana U1103 $-\mathrm{Lm} \times \mathrm{M} .30 .0860$ & … & ....... & ... & .A..... & ... & ..... & .... & ...... & ..... & … & ...... & ........s & 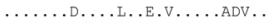 \\
\hline L. amazonensis M2269 - KE390271.1 & … & ....... & ... & .A..... & . & ..... & .... & …. & .... & & ..... & ........s & 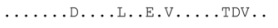 \\
\hline L. aethiopica L147 - AUMB01001544.1 & ...... & ........ & … & ..... & .. & ..... & ..... & ...... & ..... & & ...... & ..... & I...................... \\
\hline L. aethiopica L147 - AUMB01001560.1 & ... & $\ldots \ldots$ & $\ldots$ & ........ & $\ldots$ & ..... & $\ldots \ldots$ & ....... & $\ldots \ldots$ & ( & ...... & $\ldots \ldots \ldots \ldots \ldots \ldots$ & I.....D........ \\
\hline L. braziliensis M2904 - LbrM.31.1020 & & ........ & ... & . A..... & ... & ..... & ..... & ....n. & V...T & $\cdots$ & ..... & .I...V.....SQ.LG & W.N.EE....A.E.V.D...... \\
\hline L. braziliensis M2903 - LbrM2903_31_1140| & & & $\ldots$. & .A.. & & & ..... & .....N. & V...T & &. .Y. & .I....V.....SQ.LG & ...N. .E. \\
\hline
\end{tabular}

Fig. 2 Local alignment of specific Rab GTPase like protein domains. Domains were first identified and extracted from the L. major HV P25 Rab GTPase like sequence and from its selection of orthologs, then aligned. The alignment was edited in a way to shed light on the variable sites by marking all identical residues with dots

IFN- $\gamma$ levels were significantly higher in response to SLA in CCLm (Mean \pm SD: 6,124.39 $\pm 5,363.13 \mathrm{pg} / \mathrm{ml})$, HHRLm $(12,351.75 \pm 9,364.14 \quad \mathrm{pg} / \mathrm{ml})$ and $\mathrm{HHR} L i$ $(23,106.75 \pm 8,929.51 \mathrm{pg} / \mathrm{ml})$ when compared to HLR group $(52.03 \pm 84.99 \mathrm{pg} / \mathrm{ml}) \quad\left(\chi^{2}=31.875, \quad d f=1, \quad P=\right.$ 0.0001; $\chi^{2}=25.500, d f=1, P=0.0001$; and $\chi^{2}=30.136$, $d f$ $=1, P=0.0001$, respecively) (Fig. $3 \mathrm{a}$ ). We showed that the full-length rLmlRAB protein was able to induce high significant levels of IFN- $\gamma$, in CCLm and HHRLi groups $(3,720.65 \pm 3,502.28$ and $6,252.08 \pm 3,984.55 \mathrm{pg} / \mathrm{ml}$, respectively) ( $Z=4.597, P \leq 0.0001 ; Z=4.457, P \leq 0.0001$, respectively, when compared to unstimulated cultures). This rLmlRAB-induced IFN- $\gamma$ response was significantly higher than that observed in HLR group $(1,098.33 \pm$ $1,105.13 \mathrm{pg} / \mathrm{ml} ; X^{2}=19.7, d f=1, P=0.0001$ ) (Fig. 3a). Interestingly, the divergent $C$ terminal part rLmIRABC

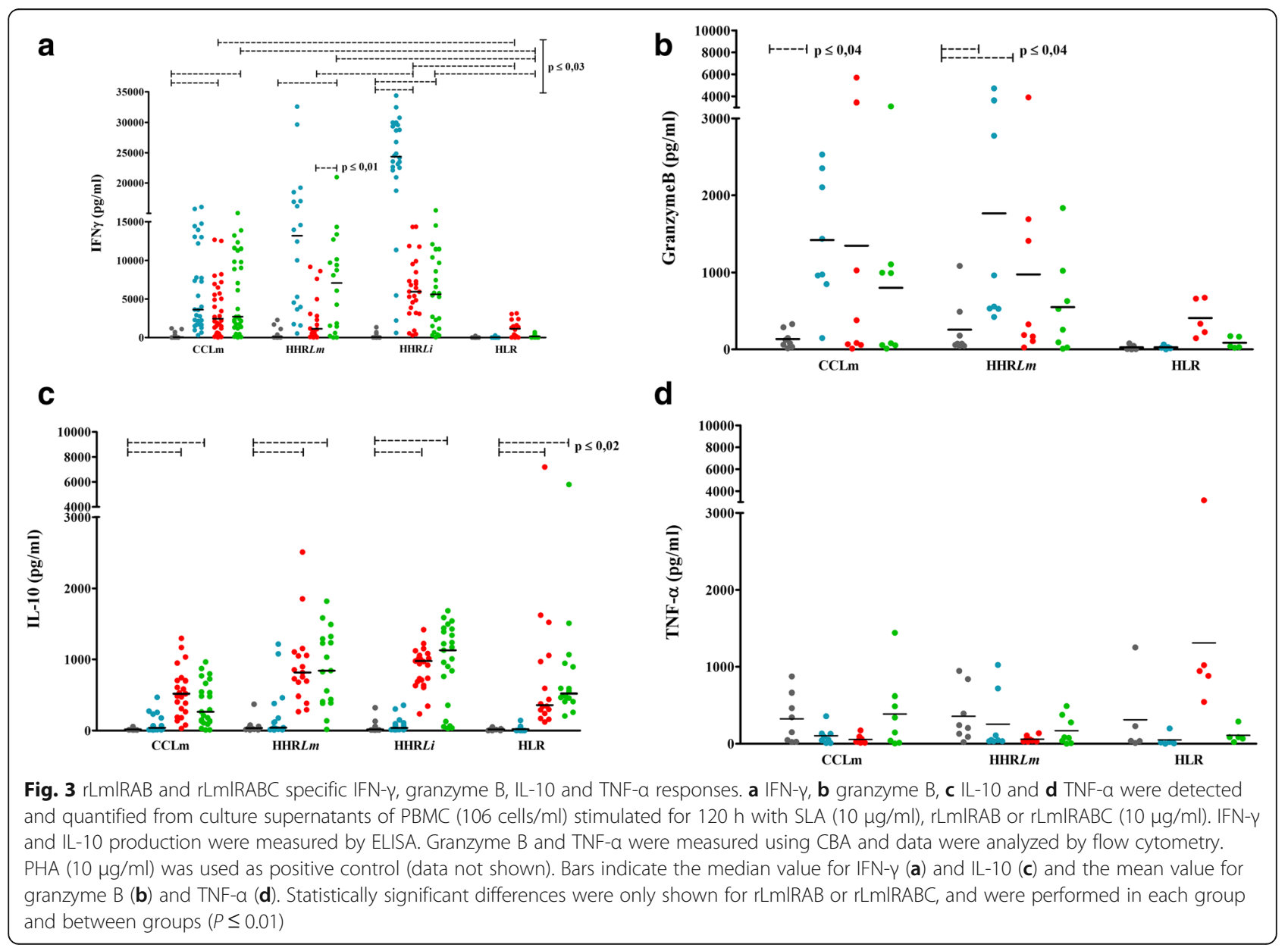


were able to induce high significant levels of IFN- $\gamma$ in all immune groups: CCLm $(5,540.05 \pm 4,984.83 \mathrm{pg} / \mathrm{ml})$, HHRLm $(6,858.70 \pm 6,084.36 \mathrm{pg} / \mathrm{ml})$ and HHR $L i$ $(5911.01 \pm 4859.83 \mathrm{pg} / \mathrm{ml})$ groups $(Z=4.782, P \leq 0.0001$; $Z=3.549, P \leq 0.0001 ; Z=4.286, P \leq 0.0001$, respectively). This IFN- $\gamma$ response was also specific since it was significantly higher in comparison with naïve controls $\left(209.9 \pm 216.81 \mathrm{pg} / \mathrm{ml} ; \chi^{2}=21.824, d f=1, P=0.0001 ; \chi^{2}\right.$ $=12.942, \quad d f=1, \quad P=0.0003 ; \quad X^{2}=13.297, \quad d f=1, \quad P=$ 0.0001 , respectively) (Fig. $3 \mathrm{a}$ ). The full protein seems to be more immunogenic in individuals immune to $L$. infantum infection, since LmlRAB induced significantly higher IFN- $\gamma$ levels in L. infantum compared to L. major immune groups. It should be noted that IFN- $\gamma$ levels were significantly higher in response to rLmRABC when compared to rLmlRAB stimulation in individuals immune to $L$. major infection. Significant levels of granzyme B were detected in response to SLA stimulation in $\operatorname{CCLm}(1,345.36 \pm 2,015.07 \mathrm{pg} / \mathrm{ml})$ and HHRLm $(1,766 \pm$ $1,698 \mathrm{pg} / \mathrm{ml})(Z=2.521, P=0.011 ; Z=2.521, P=0.011$, respectively) but not in HLR group (Fig. $3 \mathrm{~b}$ ). The rLmlRAB was able to induce significant granzyme $B$ response in HHRLm $(976.33 \pm 1,341 \mathrm{pg} / \mathrm{ml})$ while inducing lower but significant production in HLR group (407.34 $\pm 245.71 \mathrm{pg} / \mathrm{ml}) \quad(Z=2.380, P=0.017 ; \quad Z=2.023, \quad P=$ 0.043 , respectively). A high granzyme $\mathrm{B}$ response, although not significant when compared to unstimulated cultures, was observed in CCLm group $(1,345.36 \pm$ $2,015 \mathrm{pg} / \mathrm{ml})$. This result could be due to the great variability observed in granzyme B levels in CCLm individuals together with the relative low number of samples. This cytokine was not significantly detected in response to rLmlRABC stimulation. Granzyme B response could not be analysed in HHRLi group. As expected, no IL-10 was observed in response to SLA. The full-length rLmIRAB as well as its divergent part rLmlRABC induced high significant levels of IL-10 in immune as well as in naïve groups, indicating that IL-10 production was not a feature of Leishmania stimulation (Fig. 3c). Interestingly, IFN- $\gamma / \mathrm{IL}-10$ ratio were $6.8 ; 2.7$ and 7 for rLmIRAB and 14.8; 7.7 and 6.2 for rLmIRABC in CCLm, HHRLm and HHRLi, respectively. These data suggest that IL-10 inducing-capacity of rLmlRAB and rLmIRABC did not alter the ability of both proteins to induce high IFN- $\gamma$ levels. TNF- $\alpha$ was not observed at significant levels after SLA or rLmlRAB/rLmIRABC stimulation (Fig. 3d).

\section{rLmIRAB and rLmIRABC induce specific IFN- $\gamma$-producing $C D 4+$ and $C D 8+T$ cells in individuals cured of $L$. major infection}

Phenotypic analysis of $\mathrm{T}$ cells producing IFN- $\gamma$ in response to rLmlRAB and rLmIRABC was performed in CCLm group $(n=8)$ (Fig. 4). Results were compared to
SLA-specific IFN- $\gamma$ producing $\mathrm{T}$ cell responses. SLA induced a significant increase in the percentage of IFN$\gamma$-producing CD4 $+\mathrm{T}$ cells (mean $\pm \mathrm{SD}: 3.72 \pm 2.06 \%$ ) as well as IFN- $\gamma$-producing CD8+ T cells $(6.87 \pm 3.73 \%)$ among total $\mathrm{T}$ CD4+ cells $(62.95 \pm 5.94 \%$, data not shown) and total T CD8+ cells $(46.78 \pm 4.29 \%$, data not shown), respectively $(P=0.018)$. Interestingly, we showed a significantly higher percentage of $\mathrm{CD} 4+\mathrm{T}$ cells producing IFN $-\gamma(2.52 \pm 1.12 \%)$ among total $\mathrm{CD} 4+\mathrm{T}$ cells $(59.85 \pm 3.70 \%)$, after rLmlRAB stimulation in CCLm individuals, in comparison to non-stimulated cultures $(Z=-2.366, P=0.018)$ (Fig. 4a). A significant increase was also observed in the percentage of IFN- $\gamma$ producing CD8+ T cells $(6.02 \pm 1.80 \%)$ among total CD8 $+\mathrm{T}$ cells $(49.91 \pm 4.43 \%)(Z=-2.366, P=0,018)$ (Fig. $4 \mathrm{~b})$. Interestingly, the divergent rLmlRABC was also able to induce a significant increase in the percentage of both IFN- $\gamma$-producing CD4+ T cells $(2.28 \pm 1.19 \%)$ and IFN$\gamma$-producing CD8 $+\mathrm{T}$ cells $(4.42 \pm 2.49 \%)$ among total $\mathrm{CD} 4+\mathrm{T}$ cells $(59.3 \pm 3.56 \%)$ and total $\mathrm{CD} 8+\mathrm{T}$ cells (52.51 $\pm 1.9 \%)$, respectively $(Z=-2.366, P=0.018)$, in CCLm individuals (Fig. 4).

\section{Discussion}

Advances in our understanding of Leishmania infection pathogenesis and the generation of host protective immunity, together with completed Leishmania genome sequences, has opened new avenues for vaccine research. To date, only one recombinant polyprotein Leishmania vaccine candidate, LEISH-F1, has entered phase II clinical human testing [20] and the need for the identification of new vaccine candidate molecules is crucial. We previously described a Leishmania specific gene encoding a large 610 amino acid RAB GTPase (LmlRAB) that is over-expressed in parasites infecting human or mouse macrophages [13, 21, 22]. It is encoded by a single copy Lmlrab gene highly conserved between Leishmania species, while displaying a relative low level of homology with mammalian homologues. This protein is characterized by a carboxy-terminal part extension only found in the genus Leishmania, suggesting that LmlRAB is a Leishmania-specific protein [13]. A role in phagosome maturation, regulation of the secretory pathway, regulation of both uptake and degradation of endocytosed hemoglobin, was described for RAB proteins in Leishmania parasites [16-18]. The present study aimed to evaluate the immunogenicity of the recombinant LmIRAB protein as well as its divergent carboxy terminal part rLmIRABC, in individuals who have developed a protective immunity against $L$. major or $L$. infantum infection. We showed that both proteins were able to induce high significant levels of IFN- $\gamma$, in individuals with a probable asymptomatic $L$. major or $L$. infantum infection or recovered from CL. It is well 

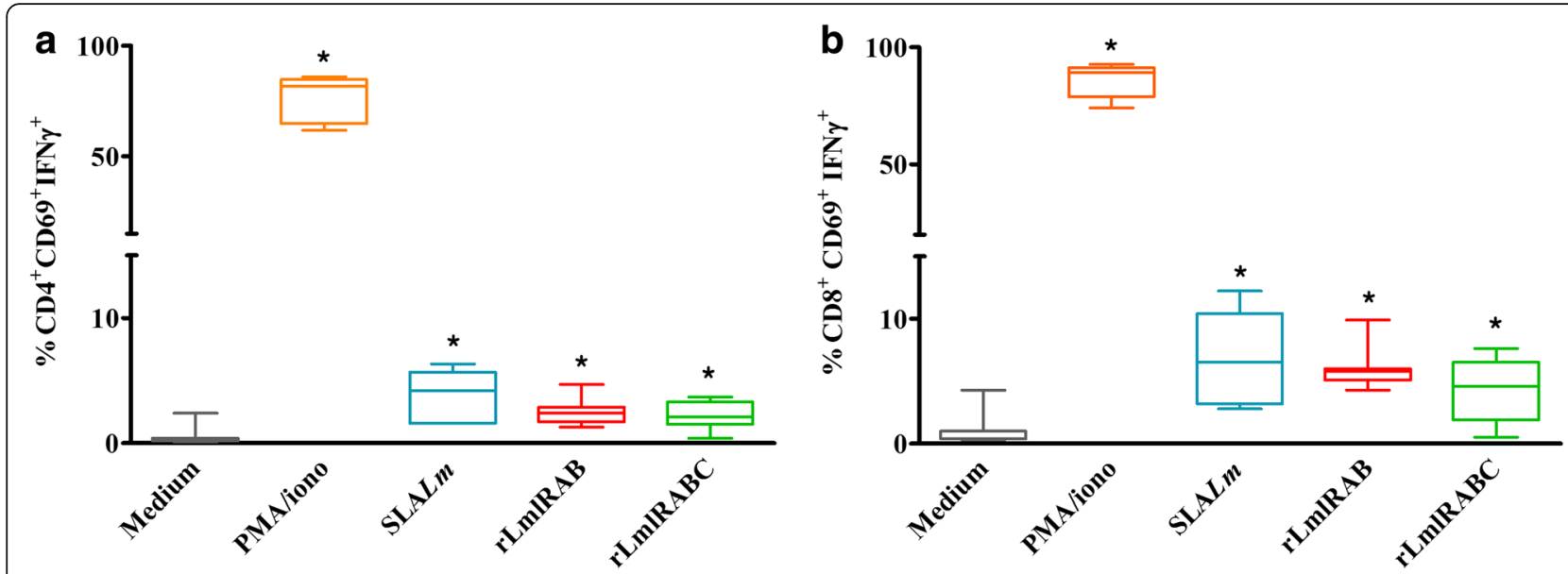

Fig. 4 Phenotype of IFN- $\gamma$ producing cells. PBMC were stimulated with PMA (50 ng/ml)/ionomicyn (10-6 M) for $6 \mathrm{~h}$ (positive controls), SLA $(10 \mu \mathrm{g} / \mathrm{ml})$, rLmIRAB or rLmIRABC $(10 \mu \mathrm{g} / \mathrm{ml})$ for $120 \mathrm{~h}$. For intracellular IFN- $\gamma$ detection, cells were treated with Golgistop for the last $6 \mathrm{~h}$ of culture, fixed and permeabilized using BD Cytoperm/cytofix kit. Data were analyzed by BD FACS Canto II. Results represent the frequency of IFN- $\gamma$ producing cells among the CD3 + CD4+ (a) and CD3 + CD8+ (b) cell populations. Wilcoxon signed-rank test was used to compare percentage of cells producing INF- $Y$ (horizontal bars inside the box indicate median values). *Statistically significant differences from stimulated and non-stimulated cultures $(P<0.05)$

established that IFN- $\gamma$ is a key effector cytokine crucial to eliminate Leishmania parasites [23]. IFN- $\gamma$ levels were significantly higher in response to rLmlRABC when compared to rLmIRAB stimulation in individuals immune to L. major infection, suggesting that more $\mathrm{T}$ cell epitopes could be located in the most divergent region of the protein. Similar IFN- $\gamma$ inducing capacity was observed for both proteins in L. infantum immune individuals. Surprisingly, the full protein induced significantly higher IFN- $\gamma$ levels in L. infantum compared to L. major immune groups, suggesting that rLmlRAB could be more immunogenic in individuals immune to L. infantum infection. Various factors can influence immunogenicity of a protein such as differences in amino acid sequences, immunogenic dominant epitopes, individualrelated factors including immune status and genetic features. Similarly, to these results, we have recently demonstrated that LaPSA-38S, a L. amazonensis promastigote surface antigen, induced high specific IFN- $\gamma$ levels in individuals immune to L. major and L. infantum infection [24]. Our previous data and those of other authors have shown Leishmania protein-specific IFN- $\gamma$ levels, in immune individuals [25-27]. We further showed in this study, a significant increase in the percentage of rLmlRAB and rLmlRABC-specific IFN- $\gamma$ producing $\mathrm{CD} 4+$ as well as $\mathrm{CD} 8+\mathrm{T}$ cells, in $\mathrm{CL}$ recovered individuals. Several studies have shown that specific CD4+ $\mathrm{T}$ cells induced by total Leishmania antigen stimulation were the main source of IFN- $\gamma[10,11,28-$ 30]. However, few studies have analysed phenotypes of cytokine-producing $\mathrm{T}$ cells in response to defined Leishmania antigens in humans. We previously showed that
LaPSA-38S stimulation was associated with an increase in $\mathrm{CD} 4+\mathrm{T}$ cells producing IFN- $\gamma$ $\square$ in individuals recovered from CL [24]. Other Leishmania proteins were described to induce CD4+ T cells producing IFN $-\gamma$ in Leishmania asymptomatic individuals [31, 32]. CD8+ T cells were also involved in protection during human Leishmania infection [31-34] and were more recently described as a source of IFN- $\gamma$ production in response to total antigens $[9,35,36]$. However, studies reporting the contribution of Leishmania-specific CD8+ T cells in IFN- $\gamma$ production following defined antigens stimulation are scarce [37, 38]. The capacity of rLmIRAB and rLmIRABC to induce granzyme $B$ production was also assessed in this work. Granzyme B is a cytolytic protein expressed by memory CD8+ and CD4+ T cells [39], which has been associated with a good prognosis in human L. major and L. mexicana CL patients [40, 41]. More recently, high levels of granzyme $\mathrm{B}$ as well as activated CD8+ T cells were observed in response to SLA in healed VL or PKDL individuals, indicating a possible role of CD8+ $\mathrm{T}$ cells in resistance to infection, via the perforin-granzyme B pathway [12, 42]. Furthermore, granzyme B-mediated elimination of intracellular protozoan parasites including Leishmania, was reported [43]. We showed that rLmlRAB protein was able to induce significant granzyme B levels in individuals with immunity to $L$. major infection. However, low but significant granzyme B levels were also detected in naïve group. Given the small sample sizes and the great variability observed in individual responses, these results need to be confirmed in larger groups and does not support the fact that this granzyme B production is not a feature of 
Leishmania infection. We recently showed a specific and significant production of granzyme $\mathrm{B}$ in response to LaPSA-38S protein in individuals with immunity to $L$. major [24]. Excreted/secreted Leishmania antigens or peptides were also described to induce granzyme B in healed $\mathrm{CL}$ individuals. With regard to the antiinflammatory IL-10 cytokine, we showed that rLmlRAB and rLmlRABC induced significant levels of this cytokine in immune individuals as well as in healthy subjects. IL-10 is produced by different cell populations including macrophages, Th2 and different regulatory $\mathrm{CD} 4+\mathrm{T}$ subsets and has been demonstrated to have regulatory effects on immune responses and pathology [44]. Although IL-10 overproduction has been associated to parasite persistence and disease establishment [45, 46], this cytokine may also play a role in controlling the excessive inflammatory response, when produced by inducible Treg cells (CD4 + CD25-FoxP3-), during acute infection [47]. rLmlRAB and rLmlRABC-induced IL-10 observed in immune as well as naïve individuals suggest that both proteins may contain cross-reactive epitopes that can be recognized by $\mathrm{T}$ cells of the majority of individuals and that this response was not a feature of Leishmania infection. IL-10 induction in PBMC from both immune and healthy individuals has already been described for other Leishmania recombinant proteins [24-26, 48, 49]. It should be noted that the presence of IL-10 did not prevent a strong IFN- $\gamma$-induced response to $\mathrm{rLmIRAB}$ proteins and high IFN- $\gamma / \mathrm{IL}-10$ ratios were observed, suggesting that the IL-10 inducing capacity of both proteins does not exclude them as potential candidate vaccines. It has been shown that high ratio of IFN $-\gamma$ to IL-10 provided the best correlate of protective immunity and it has been suggested that a correct balance of pro-inflammatory to regulatory cytokines may be involved in the outcome of human leishmaniasis and in the prediction of vaccine success $[50,51]$.

\section{Conclusion}

In summary, we demonstrated that rLmlRAB and rLmIRABC are able to induce a predominant Th1 response in individuals immune to L. major or L. infantum, making this protein a potential cross-species vaccine candidate. As far as we know, only one study has reported the immunogenicity of a RAB antigen in a parasitic disease [52]. Our results deserve further investigations to evaluate these vaccine candidates in combination with other promising immunogenic antigens such as salivary gland proteins. Moreover, since synthetic peptide-based vaccines are the potential future of vaccination, identification of such vaccines candidates from LmIRAB proteins are under progress in our laboratory.

\section{Abbreviations}

CBA: Cytometric bead array; CD4: Cluster of differentiation 4; CD69: Cluster of differentiation 69; CD8: Cluster of differentiation 8; CpG-ODN: CpG oligodeoxynucleotides; ELISA: Enzyme-linked immunosorbent assay;

GTP: Guanosine-5'-triphosphate; IFN- $\gamma$ : Interferon-gamma; IL-10: Interleukin-10; IL-13: Interleukin-13; IL-2: Interleukin-2; IL-4: Interleukin-4; IL-5: Interleukin-5; NO: Nitric oxide; PBMC: Peripheral blood mononuclear cells; PMA: Phorbo 12Myristate 13-Acetate; RAB: Ras-related proteins in brain; RPMI-1640: Roswell Park Memorial Institute 1640 medium; SLA: Soluble Leishmania antigen; TGF $\beta$ : Transforming growth factor beta; Th1: Type 1 T helper lymphocytes; Th2: Type 2 T helper lymphocytes; TNFa: Tumor Necrosis Factor-alpha

\section{Acknowledgements}

The authors thank W. Markikou-Ouni, E. Petitdidier, R. Bras-Gonçalves, Z. Ben Lasfer, A. N. Ben Khalaf and J. L. Lemesre for their professional assistance in laboratory work. Authors are also grateful to the staff of the Regional Directorate of Public Health of Kairouan, Tunisia.

\section{Funding}

Funding was provided by IMM23, Tunisian Ministry for research and technology. This work was also partially funded by EU's Seventh Framework Programme (FP7) (RAPSODI project, grant agreement number 223341). The funders had no role in study design, data collection and analysis, decision to publish, or preparation of the manuscript.

\section{Availability of data and materials}

Not applicable.

\section{Authors' contributions}

Conceived and designed the experiments: AMG, MC and RCA. Performed the experiments: RCA. Analysed the data: AMG, MC, RCA, NBJ and ASC.

Coordinated the recruitment and sampling: KA. Wrote the paper: RCA, AMG

and MC. All authors read and approved the final manuscript.

\section{Competing interests}

The authors declare that they have no competing interests.

\section{Consent for publication}

Not applicable.

\section{Ethics approval and consent to participate}

The recruitment and sampling collection of different groups of volunteers was done in accordance with Good Clinical Practice (GCP), based on the recommendations and approval of the local ethical Committee of Institut Pasteur de Tunis (IPT) (PV 10/07. February 25, 2010). A written informed consent was obtained from all subjects involved in this study.

\section{Publisher's Note}

Springer Nature remains neutral with regard to jurisdictional claims in published maps and institutional affiliations.

\section{Author details}

${ }^{1}$ Laboratory of Medical Parasitology, Biotechnology and Biomolecules, LR11-IPT-06, Institut Pasteur de Tunis, Tunis, Tunisia. ${ }^{2}$ University of Carthage, Tunis, Tunisia. ${ }^{3}$ Molecular Epidemiology and Experimental Pathology Applied to Infectious Diseases Laboratory, Institut Pasteur de Tunis, Tunis, Tunisia.

${ }^{4}$ Institut Polytechnique LaSalle Beauvais, Beauvais, France.

Received: 19 July 2016 Accepted: 4 April 2017

Published online: 17 April 2017

\section{References}

1. Alvar J, Vélez ID, Bern C, Herrero M, Desjeux P, Cano J, et al. Leishmaniasis worldwide and global estimates of its incidence. PLoS One. 2012;7:e35671.

2. Oliveira LF, Schubach AO, Martins MM, Passos SL, Oliveira RV, Marzochi MC, et al. Systematic review of the adverse effects of cutaneous leishmaniasis treatment in the New World. Acta Trop. 2011;118:87-96.

3. Liew FY, Li Y, Millott S. Tumor necrosis factor-alpha synergizes with IFNgamma in mediating killing of Leishmania major through the induction of nitric oxide. J Immunol. 1990;145:4306-10. 
4. Sacks D, Noben-Trauth $N$. The immunology of susceptibility and resistance to Leishmania major in mice. Nat Rev Immunol. 2002;2:845-58.

5. Scott P, Artis D, Uzonna J, Zaph C. The development of effector and memory $T$ cells in cutaneous leishmaniasis: the implications for vaccine development. Immunol Rev. 2004;201:318-38.

6. Scott P, Pearce E, Cheever AW, Coffman RL, Sher A. Role of cytokines and CD4+ T-cell subsets in the regulation of parasite immunity and disease. Immunol Rev. 1989;112:161-82.

7. Ajdary S, Alimohammadian MH, Eslami MB, Kemp K, Kharazmi A. Comparison of the immune profile of nonhealing cutaneous leishmaniasis patients with those with active lesions and those who have recovered from infection. Infect Immun. 2000;68:1760-4.

8. Castellano LR, Filho DC, Argiro L, Dessein H, Prata A, Dessein A, et al. Th1/ Th2 immune responses are associated with active cutaneous leishmaniasis and clinical cure is associated with strong interferon-gamma production. Hum Immunol. 2009;70:383-90

9. Nateghi Rostami M, Keshavarz H, Edalat R, Sarrafnejad A, Shahrestani T, Mahboudi F, et al. CD8+ T cells as a source of IFN- $\gamma$ production in human cutaneous leishmaniasis. PLoS Negl Trop Dis. 2010;4:e845.

10. Kumar R, Singh N, Gautam S, Singh OP, Gidwani K, Rai M, et al. Leishmania specific CD4 T cells release IFNy that limits parasite replication in patients with visceral leishmaniasis. PLoS Negl Trop Dis. 2014;8:e3198.

11. da Silva Santos C, Brodskyn CI. The Role of CD4 and CD8 T Cells in human cutaneous leishmaniasis. Front Public Health. 2014;2:165.

12. Kaushal H, Bras-Gonçalves R, Negi NS, Lemesre J-L, Papierok G, Salotra P. Role of CD8(+) T cells in protection against Leishmania donovani infection in healed visceral leishmaniasis individuals. BMC Infect Dis. 2014;14:653.

13. Chenik M, Chaabouni N, Ben Achour-Chenik Y, Ouakad M, Lakhal-Naouar I, Louzir $\mathrm{H}$, et al. Identification of a new developmentally regulated Leishmania major large RAB GTPase. Biochem Biophys Res Commun. 2006; 341:541-8.

14. Zhen Y, Stenmark H. Cellular functions of Rab GTPases at a glance. J Cell Sci. 2015;128:3171-6.

15. Singh SB, Tandon R, Krishnamurthy G, Vikram R, Sharma N, Basu SK, et al. Rab5-mediated endosome-endosome fusion regulates hemoglobin endocytosis in Leishmania donovani. EMBO J. 2003:22:5712-22.

16. Patel N, Singh SB, Basu SK, Mukhopadhyay A. Leishmania requires Rab7mediated degradation of endocytosed hemoglobin for their growth. Proc Natl Acad Sci U S A. 2008;105:3980-5.

17. Bahl S, Parashar S, Malhotra H, Raje M, Mukhopadhyay A. Functional characterization of monomeric GTPase Rab1 in the secretory pathway of Leishmania. J Biol Chem. 2015;290:29993-30005.

18. Rastogi R, Verma JK, Kapoor A, Langsley G, Mukhopadhyay A. Rab5 isoforms specifically regulate different modes of endocytosis in Leishmania. J Biol Chem. 2016;291(28):14732-46.

19. Kearse M, Moir R, Wilson A, Stones-Havas S, Cheung M, Sturrock S, et al. Geneious Basic: an integrated and extendable desktop software platform for the organization and analysis of sequence data. Bioinforma Oxf Engl. 2012;28:1647-9.

20. Chakravarty J, Kumar S, Trivedi S, Rai VK, Singh A, Ashman JA, et al. A clinical trial to evaluate the safety and immunogenicity of the LEISH-F1 + MPL-SE vaccine for use in the prevention of visceral leishmaniasis. Vaccine. 2011;29:3531-7.

21. Dillon LA, Suresh R, Okrah K, Corrada Bravo H, Mosser DM, El-Sayed NM. Simultaneous transcriptional profiling of Leishmania major and its murine macrophage host cell reveals insights into host-pathogen interactions. BMC Genomics. 2015;16:1108

22. Fernandes MC, Dillon LA, Belew AT, Bravo HC, Mosser DM, El-Sayed NM. Dual transcriptome profiling of Leishmania-infected human macrophages reveals distinct reprogramming signatures. MBio. 2016;7(3):e00027-16.

23. Kima PE, Soong L. Interferon gamma in leishmaniasis. Front Immunol. 2013;4:156.

24. Chamakh-Ayari R, Bras-Gonçalves R, Bahi-Jaber N, Petitdidier E, MarkikouOuni W, Aoun K, et al. In vitro evaluation of a soluble Leishmania promastigote surface antigen as a potential vaccine candidate against human leishmaniasis. PLoS One. 2014;9:e92708.

25. Lakhal-Naouar I, Boussoffara T, Meddeb-Garnaoui A, Ben Achour-Chenik Y, Louzir H, Chenik M. Cellular and humoral responses to Leishmania major virulence factors in healed cutaneous leishmaniasis and Mediterranean visceral leishmaniasis patients. Clin Vaccine Immunol CVI. 2009;16:956-8.

26. Meddeb-Garnaoui A, Toumi A, Ghelis H, Mahjoub M, Louzir H, Chenik M. Cellular and humoral responses induced by Leishmania histone $\mathrm{H} 2 \mathrm{~B}$ and its divergent and conserved parts in cutaneous and visceral leishmaniasis patients, respectively. Vaccine. 2010;28:1881-6.

27. Kushawaha PK, Gupta R, Sundar S, Sahasrabuddhe AA, Dube A. Elongation factor-2, a Th1 stimulatory protein of Leishmania donovani, generates strong IFN- $\gamma$ and IL-12 response in cured Leishmania-infected patients/hamsters and protects hamsters against Leishmania challenge. J Immunol. 2011;187:6417-27.

28. Bottrel RL, Dutra WO, Martins FA, Gontijo B, Carvalho E, Barral-Netto M, et al. Flow cytometric determination of cellular sources and frequencies of key cytokine-producing lymphocytes directed against recombinant LACK and soluble Leishmania antigen in human cutaneous leishmaniasis. Infect Immun. 2001;69:3232-9.

29. da Santos C S, Boaventura V, Ribeiro Cardoso C, Tavares N, Lordelo MJ, Noronha $A$, et al. CD8(+) granzyme B(+)-mediated tissue injury vs. CD4(+)IFNy(+)-mediated parasite killing in human cutaneous leishmaniasis. J Invest Dermatol. 2013;133:1533-40.

30. Carvalho AM, Magalhães A, Carvalho LP, Bacellar O, Scott P, Carvalho EM. Immunologic response and memory T cells in subjects cured of tegumentary leishmaniasis. BMC Infect Dis. 2013;13:529.

31. Stäger S, Rafati S. CD8(+) T cells in leishmania infections: friends or foes? Front Immunol. 2012;3:5

32. Da-Cruz AM, Conceição-Silva F, Bertho AL, Coutinho SG. Leishmania-reactive CD4+ and CD8+ T cells associated with cure of human cutaneous leishmaniasis. Infect Immun. 1994;62:2614-8

33. Maasho K, Sanchez F, Schurr E, Hailu A, Akuffo H. Indications of the protective role of natural killer cells in human cutaneous leishmaniasis in an area of endemicity. Infect Immun. 1998;66:2698-704.

34. Novais FO, Scott P. CD8+ T cells in cutaneous leishmaniasis: the good, the bad, and the ugly. Semin Immunopathol. 2015;37:251-9.

35. Khamesipour A, Nateghi Rostami M, Tasbihi M, Miramin Mohammadi A, Shahrestani T, Sarrafnejad A, et al. Phenotyping of circulating CD8 ${ }^{+} T$ cell subsets in human cutaneous leishmaniasis. Microbes Infect Inst Pasteur. 2012;14:702-11.

36. Cardoso TM, Machado Á, Costa DL, Carvalho LP, Queiroz A, Machado P, et al. Protective and pathological functions of CD8+ T cells in Leishmania braziliensis infection. Infect Immun. 2015:83:898-906.

37. Bourreau E, Pascalis H, Prévot G, Kariminia A, Jolly N, Milon G, et al. Increased production of interferon-gamma by Leishmania homologue of the mammalian receptor for activated $C$ kinase-reactive CD4+ T cells among human blood mononuclear cells: an early marker of exposure to Leishmania? Scand J Immunol. 2003;58:201-10.

38. Seyed N, Zahedifard F, Safaiyan S, Gholami E, Doustdari F, Azadmanesh K, et al. In silico analysis of six known Leishmania major antigens and in vitro evaluation of specific epitopes eliciting HLA-A2 restricted CD8 T cell response. PLoS Negl Trop Dis. 2011;5:e1295.

39. Lin L, Couturier J, Yu X, Medina MA, Kozinetz CA, Lewis DE. Granzyme B secretion by human memory CD4 T cells is less strictly regulated compared to memory CD8 T cells. BMC Immunol. 2014;15:36.

40. Bousoffara T, Louzir H, Ben Salah A, Dellagi K. Analysis of granzyme B activity as a surrogate marker of Leishmania-specific cell-mediated cytotoxicity in zoonotic cutaneous leishmaniasis. J Infect Dis. 2004;189:1265-73.

41. Hernández-Ruiz J, Salaiza-Suazo N, Carrada G, Escoto S, Ruiz-Remigio A, Rosenstein Y, et al. CD8 cells of patients with diffuse cutaneous leishmaniasis display functional exhaustion: the latter is reversed, in vitro, by TLR2 agonists. PLoS Negl Trop Dis. 2010;4:e871.

42. Kaushal H, Bras-Gonçalves R, Avishek K, Kumar Deep D, Petitdidier E, Lemesre J-L, et al. Evaluation of cellular immunological responses in monoand polymorphic clinical forms of post-kala-azar dermal leishmaniasis in India. Clin Exp Immunol. 2016:185:50-60.

43. Dotiwala F, Mulik S, Polidoro RB, Ansara JA, Burleigh BA, Walch M, et al. Killer lymphocytes use granulysin, perforin and granzymes to kill intracellular parasites. Nat Med. 2016;22:210-6.

44. Sabat R, Grütz G, Warszawska K, Kirsch S, Witte E, Wolk K, et al. Biology of interleukin-10. Cytokine Growth Factor Rev. 2010;21:331-44.

45. Belkaid Y, Piccirillo CA, Mendez S, Shevach EM, Sacks DL. CD4 + CD25+ regulatory $T$ cells control Leishmania major persistence and immunity. Nature. 2002;420:502-7.

46. Bourreau E, Ronet C, Darsissac E, Lise M-C, Marie DS, Clity E, et al. In leishmaniasis due to Leishmania guyanensis infection, distinct intralesional interleukin-10 and Foxp3 mRNA expression are associated with unresponsiveness to treatment. J Infect Dis. 2009;199:576-9. 
47. Anderson CF, Oukka M, Kuchroo VJ, Sacks D. CD4(+)CD25(-)Foxp3(-) Th1 cells are the source of IL-10-mediated immune suppression in chronic cutaneous leishmaniasis. J Exp Med. 2007;204:285-97.

48. de Carvalho LP, Soto M, Jerônimo S, Dondji B, Bacellar O, Luz V, et al. Characterization of the immune response to Leishmania infantum recombinant antigens. Microbes Infect Inst Pasteur. 2003;5:7-12.

49. Carvalho LP, Passos S, Dutra WO, Soto M, Alonso C, Gollob KJ, et al. Effect of LACK and KMP11 on IFN-gamma production by peripheral blood mononuclear cells from cutaneous and mucosal leishmaniasis patients. Scand J Immunol. 2005;61:337-42.

50. Stober CB, Lange UG, Roberts MTM, Alcami A, Blackwell JM. IL-10 from regulatory $T$ cells determines vaccine efficacy in murine Leishmania major infection. J Immunol. 2005;175:2517-24.

51. Stober CB, Jeronimo SMB, Pontes NN, Miller EN, Blackwell JM. Cytokine responses to novel antigens in a peri-urban population in Brazil exposed to Leishmania infantum chagasi. Am J Trop Med Hyg. 2012;87:663-70.

52. Chuang C-C, Chen C-W, Su K-E, Tsai Y-T, Du W-Y. A RAB family antigen of Angiostrongylus cantonensis induces a Th1-type immune response in vitro and in vivo. Exp Parasitol. 2013;134:122-7.

Submit your next manuscript to BioMed Central and we will help you at every step:

- We accept pre-submission inquiries

- Our selector tool helps you to find the most relevant journal

- We provide round the clock customer support

- Convenient online submission

- Thorough peer review

- Inclusion in PubMed and all major indexing services

- Maximum visibility for your research

Submit your manuscript at www biomedcentral.com/submit
() BioMed Central 